\title{
Constitución Económica Europea y modelo social: límites e ineficiencias de la integración negativa mejorada en la lucha contra la exclusión social*
}

\author{
European Economic Constitution and Social Model: \\ Limits and Inefficiencies of the Improved Negative Integration \\ in the Fight Against Social Exclusion
}

Ainhoa Lasa López

Investigadora asociada del Equipo Integración Europea,

Universidad de Deusto.

\begin{abstract}
Sumario: I. Exclusión, inclusión, pobreza y vínculo económico en la crisis del paradigma globalizador.-II. El modelo social del constitucionalismo de mercado europeo: presupuestos teórico-metodológicos. 2.1. La oposición entre las constituciones económicas del Estado social y de la Unión Europea. 2.1.1. La consolidación del primado del mercado. 2.1.2. Nueva gobernanza económica europea: de la crisis a la rehabilitación del vínculo económico. 2.1.3. Funcionalidad de la integración positiva y solidaridad competitiva.-III. Traducción político-normativa de la lucha contra la pobreza. 3.1. La exclusión en el marco de la política social en el Tratado de Lisboa. 3.2. Carta Social Europea, Carta Comunitaria de los Derechos Sociales Fundamentales de los Trabajadores, Carta de Derechos Fundamentales de la Unión Europea: alcance y garantías del derecho a la protección contra la pobreza. 3.3. La Estrategia Europa 2020.-IV. Conclusiones finales. 4.1. La vacuidad de las aportaciones basadas en la regeneración social del Derecho de la Unión. 4.2. La organización del modelo social supranacional desde los parámetros del gobierno europeo de la economía como única vía para superar el déficit de la integración positiva.
\end{abstract}

Resumen: La gestión de la crisis en la Unión Europea desde la perspectiva de la racionalidad del cálculo económico se ha materializado en una serie de mecanismos que buscan consolidar la centralidad del vínculo económico, corrigiendo las deficiencias del diseño institucional de la eurozona. Por lo tanto, lejos de tratarse de una transformación que reformula la integración negativa en términos de equilibrio con la dimensión social, ahonda en el estatus de subalternidad de la integración positiva. Desde estos parámetros, el objetivo de combatir la exclusión social a escala europea deviene una quimera. La escasa virtualidad práctica de los documentos so-

* Recibido el 8 de mayo de 2015, aceptado el 8 de junio de 2015. 
ciales, la utilización de técnicas de soft law, y la devaluación del derecho a la protección contra la pobreza al limbo de la programaticidad, acentúa el carácter marginal de la respuesta social europea a la crisis.

Palabras clave: pobreza, vínculo social, gobierno de la economía, constitucionalismo de mercado europeo.

Abstract: The management of the crisis in the European Union from the perspective of rationality of economic calculation has resulted in the adoption of a series of mechanisms that seek to rehabilitate the centrality of the economic bond, correcting institutional deficiencies of the eurozone. Therefore, far from being a transformation that redefines negative integration in terms of balance with social dimension, it delves into the status of subordination of positive integration. From these parameters, the fight against exclusion at the European level becomes a chimera. The limited practical effort of the social documents, the use of soft law techniques, and the devaluation of the right to protection against poverty to the limbo of programmaticity, accentuates the marginalization of the European social answer to the crisis.

Keywords: poverty, social bond, economic government, European market constitutionalism.

"La exclusión social, y por lo tanto, la pobreza, constituye una violación de los derechos fundamentales de la persona y de la familia como núcleo central de la sociedad que puede minar el futuro de nuestras democracias".

Parlamento Europeo

\section{Exclusión, inclusión, pobreza y vínculo económico en la crisis del paradigma globalizador}

El 5 de marzo de 2015, la Comisión de Empleo y Asuntos Sociales del Parlamento Europeo (PE) en su Informe sobre el Semestre Europeo para la coordinación de las políticas económicas: aspectos sociales y relativos al empleo del Estudio Prospectivo Anual sobre el Crecimiento 2015², recordaba "que más de 122 millones de ciudadanos de la UE se encuentran en riesgo de pobreza o exclusión social, incluida la pobreza de los ocupados y la pobreza infantil", para terminar advirtiendo que "estos niveles son inaceptables y deben reducirse inmediatamente" (Considerando 67 del Informe, página 19).

$1(2014 / 2222(\mathrm{INI})$ 
De los datos del informe se desprende que la crisis del modelo jurídico político de la globalización se ha traducido en un incremento exponencial de la pobreza en la Unión. Sobre todo, si tenemos en cuenta que a mediados de los ochenta del siglo pasado el número de pobres en la entonces Comunidad Europea era de 44 millones. Estos datos implican que en treinta años Europa ha registrado un aumento de 78 millones de ciudadanos pobres, lo que refleja la gravedad de la cuestión y, al mismo tiempo, que lejos de tratarse una situación coyuntural fruto de la actual crisis, la exclusión social es un problema endémico y de naturaleza estructural.

Sin embargo, la solución empleada entonces y ahora por los Estados Miembros (EEMM) y las instituciones de la Unión ha sido la misma: la empleabilidad en clave de políticas activas propias del workfare state basadas en una infraestructura de la responsabilidad que traslada al individuo el objetivo de su propia integración social amparándose en la virtud igualadora de oportunidades de la economía social de mercado ${ }^{2}$. Desde esta óptica, no es de extrañar que los programas comunitarios que en la década de los setenta iniciaron la lucha contra la pobreza y la exclusión social, y el enfoque actual marcado por la Estrategia Europa $2020^{3}$ y la Plataforma contra la Pobreza y la Exclusión $\mathrm{Social}^{4}$, sean ineficaces en la consecución de su principal objetivo, la erradicación, o cuanto menos, la aminoración progresiva de la exclusión social.

Ahora bien, pretender localizar las causas de este fracaso en la ambigüedad de contenidos, la indefinición política, la ausencia de un dispositivo jurídico vinculante o la falta de presupuesto para conseguir su efectividad, es una lectura sesgada que olvida que el principal factor que impide abordar la pobreza en toda su complejidad es, precisamente, el propio modelo jurídico-político de la Unión. La centralidad incondicionada del mercado y sus coordenadas, maximización de la competencia y libertades económicas, piedras angulares del constitucionalismo de mercado europeo consagrado por el Tratado de Maastricht, han sido y son los principales obstáculos para revertir la imparable tasa de pobreza. Fundamentalmente, porque abordar la cuestión de la exclusión social desde los mismos parámetros que la agravan, y tratar de corregirla empleando mecanismos que generan nuevas dimensio-

${ }^{2}$ LASA LÓPEZ, A., Constitución económica y derecho al trabajo en la Unión Europea, ed. Comares, Granada, 2011, pp. 32-34.

${ }^{3}$ Comunicación de la Comisión de 3 de marzo de 2010. "Una estrategia para un crecimiento inteligente, sostenible e integrador: Europa 2020” [COM (2010) 2020 final].

${ }^{4}$ Comunicación de la Comisión al Parlamento Europeo, al Consejo, al Comité Económico y Social Europeo y al Comité de las Regiones, de 16 de diciembre de 2010. "La Plataforma Europea contra la Pobreza y la Exclusión Social: Un marco europeo para la cohesión social y territorial" [Bruselas COM(2010) 758 final]. 
nes de exclusión social, trabajadores pobres, pobreza en la tercera edad o pobreza energética, entre otras, resulta, cuanto menos, contradictorio.

Tampoco parece una solución plausible trasladar, sin más, al espacio supranacional las prerrogativas nacionales en materia social. De hecho, aunque la Unión dispusiera de competencia exclusiva en materia de política social, ésta seguiría ocupando una posición secundaria o residual en el ordenamiento jurídico europeo. La condición hiperjerárquica que detentan los valores del constitucionalismo de mercado, impiden articular una dimensión social sólida que contrarreste dicha supremacía y corrija, por ende, la asimetría relacional.

Con todo, el debate sobre la integración positiva y su necesaria tutela por el ordenamiento jurídico europeo, no es nuevo. Prueba de ello es el abundante material dedicado al estudio de esta cuestión ya desde la década de los ochenta ${ }^{5}$. La formulación de un corpus jurídico de naturaleza social al cual se le reconozca una fuerza constitucional equivalente a la decisión de sistema de una economía social de mercado, era y es una prioridad absoluta para la UE. Esta necesidad de situar la tutela de la dimensión social en el espacio legal europeo tiene su principal causa en el problema de la desconexión existente entre la integración económica y la integración social. Una disociación que se ha agravado con la afectación a las políticas de bienestar estatales de los imperativos de la integración económica ${ }^{6}$.

El punto de inflexión viene determinado por la imposición de un nuevo paradigma fruto de las transformaciones simultáneas producidas por los fenómenos de la crisis del Estado social, la globalización y la integración europea. Caracterizado por la centralidad del mercado, tiene como directa

${ }^{5}$ DÄUBLER, W., "Market and Social Justice in the EC. The rationale and substance of a European fundamental rights Act”, en DÄUBLER, W., Market and Social Justice in the EC. The other side of the internal market. 1991,ed., Güterlosh, Renania del Norte-Westfalia, 1991, pp. 177-191.LYON-CAEN, A, Y SIMITIS, S., "L'Europe sociale á la recherche de ses références, en Revue du Marché Unique Européen, n.4, 1993, pp. 109 y ss. RODRIGUEZPIÑERO, M., BRAVO-FERRER, M, y CASAS BAAMONDE, M.E., "In Support of a European Social Constitution", en DAVIS. P., (coord), European Community Labour Law: Principles and perspectives. Liber amicorum Lord Wedderburn, ed., Clarendon Press, Oxford, 1996, pp. 23 y ss. WEISS, M., "Il Trattato di Ámsterdam e la politica sociale", en Diritto delle relazioni industriali, $\mathrm{n} .{ }^{\circ}$ 1, 1998, pp. 3-9. BUNTENBACH, A., "Un cambio de rumbo para una Europa más social”, en Gaceta Sindical: reflexión y debate, n. ${ }^{\circ} 18,2012$, pp. 315320. SCHIEK, D., "The EU constitutional of social governance in an economic crisis in defence of a transnacional dimension to social Europe", en Maastricht Journal of European and Comparative Law, n. ${ }^{\circ}$ 2, 2013, pp. 185-208.

${ }^{6}$ SCHARPF, F.W., "Integrazione negative e integrazione positive: i dilemmi della costruzione europea" en Stato e Mercato, n. ${ }^{\circ}$ 1. 1998, pp. 21 y ss. FERRERA, M., "Integrazione europea e sovranitá sociale dello Stato-Nazione, en Rivista Italiana di Scienza Politica, n. ${ }^{\circ}$, 2000, pp. 393-403. 
consecuencia la disolución de los contenidos propios del constitucionalismo social. Los nuevos principios organizativos se sitúan en la lógica de la desvinculación de los mecanismos de sujeción política del Estado social, de ruptura del paradigma de la racionalización social del mercado.

Desde esta perspectiva, nuestra aproximación a la cuestión de la exclusión social se sitúa en un contexto más amplio como es el del modelo constitucional europeo que hemos definido en términos de constitucionalismo de mercado, y su actual crisis. Sin minimizar por ello el alcance de la normativa que aborda de manera más directa esta temática y que será analizada con posterioridad. El objetivo es evitar una reflexión parcial circunscrita a las carencias del articulado y demás panoplia instrumental para, de manera preferente, contextualizar la exclusión social en el marco del modelo social del constitucionalismo de mercado como su principal ámbito de materialización. Principalmente, porque situar el estado de la cuestión en un enfoque meramente descriptivo basado en el estudio aislado del dispositivo social europeo desvinculado de su condicionamiento por la constitución material europea, nos conduciría a una reflexión que no iría más allá de la introducción de mecanismos correctores del déficit social europeo de dudosa eficacia para corregir la imparable tendencia de mercantilización de la integración positiva.

Por lo tanto, el objetivo es analizar las transformaciones, en términos de ruptura con el modelo social del primado de la política, incorporadas por el primado de la economía, así como la crisis por la que atraviesa este último modelo y las medidas adoptadas para su corrección. Para ello, nuestra premisa principal es que el modelo social europeo se construye desde la ruptura del vínculo social, como elemento configurador de la constitución económica del Estado social, y su sustitución por el vínculo económico del constitucionalismo de mercado que se diferencia del primero tanto desde el punto de vista de su dimensión normativa, como del significado que otorga a la integración positiva en el espacio económico europeo.

\section{El modelo social del constitucionalismo de mercado europeo: presupuestos teórico-metodológicos}

Al hilo de lo señalado hasta el momento, consideramos que el problema no es aquel de trasladar al ámbito supranacional europeo el espacio de protección de la integración positiva, como una consecuencia inevitable del propio proceso de integración económica. Puesto que se trata de un planteamiento que minimiza las implicaciones de la constitución económica europea, reforzada en los últimos años con el engranaje normativo de la nueva Gobernanza Económica Europea (GEE), y que por lo tanto, se sitúa ajeno a 
los contenidos que definen el marco de la explicación del surgimiento del proceso de integración.

De acuerdo con una línea de discurso mayoritaria, la práctica ausencia de disposiciones sociales en los Tratados Constitutivos obedecería a un descuido intencionado por parte de los padres fundadores. Mayores divergencias plantean sus causas. Para unos, se trataba de un difícil equilibrio constitucional entre dos necesidades insoslayables: por un lado, el establecimiento de un mercado común en régimen de concurrencia guiado por los principios de la competencia y las libertades económicas de los factores de producción. Por otro lado, la preservación en el ámbito nacional de aquellos institutos vitales para la relegitimación democrática de los Estados tras el fin de la segunda guerra mundial. Una distribución de competencias entre los Estados y la Comunidad en la que los primeros tenían reservado como espacio de intervención el de la protección social, mientras que las instituciones comunitarias tenían como finalidad exclusiva la construcción de un mercado común. Un compromiso que, al mismo tiempo, funcionaba como sistema de garantías de los sistemas de bienestar nacionales. Además, la construcción de un espacio económico integrado actuaría como un estímulo para el crecimiento y la expansión de la capacidad de intervención socioeconómica de los EEMM, asegurando la apertura gradual y controlada de las respectivas economías al propio mercado común. Un mecanismo de ajuste estructural frente a la posible erosión de los sistemas de protección social por la integración económica ${ }^{7}$.

Para otros, la ausencia de una intervención normativa comunitaria en el ámbito social en los primeros estadios de la integración tuvo su origen en una decisión consciente, que buscaría la consolidación de las bases económicas del proyecto comunitario como condición necesaria para, posteriormente, poder llevar a cabo una intervención de este tipo. Ambos objetivos, la creación de un mercado común y el bienestar social, estarían presentes desde un primer momento en las intenciones de los redactores de los Tratados. Sin embargo, era necesario construir previamente la infraestructura económica para poder edificar sucesivamente las superestructuras sociales y políticas adecuadas. Ilustrativo de este "marxismo preterintencional de los padres fundadores" sería el artículo 2 del Tratado de Roma, donde los objetivos del "desarrollo armonioso de las actividades económicas", "el crecimiento continúo y equilibrado" y el "incremento del nivel de vida", son

7 GIUBBONI, S., "Da Roma a Nizza. Libertá economiche e diritti sociali fondamentali nell'Unione Europea", en Quaderni di diritto del lavoro e delle relazioni industriali, n. 27. 2004, pp. 10-12. Del mismo autor, "Verso la Costituzione Europea: la traiesttoria dei diritti fondamentali nell'ordinamento comunitario", en Rivista del diritto della sicurezza sociale, n. ${ }^{\circ} 2,2004$, p. 491. 
confiados tanto al libre funcionamiento del mercado común, como a la progresiva aproximación de las actividades económicas. ${ }^{8}$.

Lo que realmente nos interesa poner de relieve de ambas reflexiones no es tanto las diferencias que pudieran existir entre una y otra, sino que ambas reproducen los términos del debate de una manera equívoca. Al minimizar la tensión ya existente en la primera fase de la integración entre el modelo de bienestar social, propio del constitucionalismo social, con el nuevo paradigma, se menoscaban las repercusiones jurídicas que este último introduce. Esta minusvaloración se contagia también a los sistemas de protección social, en la medida en que su continuidad operativa en el ordenamiento europeo parecería no estar condicionada por las decisiones fundamentales que la constitución económica europea incorpora. La independencia de los EEMM en el ámbito económico, junto con la falta de un sistema europeo de protección social por las razones apuntadas, implicaría de acuerdo con la primera de las tesis, la preservación del sistema de bienestar en el ámbito interno a salvo de los efectos desplegados por la integración económica comunitaria en la forma preeminente de la integración negativa.

La ruptura del compromiso de los orígenes, con la consiguiente pérdida de autonomía de los países miembros en el ámbito económico y social, sitúa ahora a la UE como espacio de protección preferente de los sistemas de bienestar. No obstante, el problema de trasladar al nivel europeo la construcción de un sistema de protección social desplaza la cuestión al reparto de competencias y a los niveles de acción. Mientras la integración económica actúa redefiniendo los sistemas de bienestar nacionales, en la instancia europea se mantienen las estructuras e institutos jurídicos propios de la garantía de la libertad del mercado. La introducción en los sucesivos Tratados de fórmulas de soft law, como la coordinación de las políticas sociales o el método abierto de coordinación (MAC) en la lucha contra la pobreza y la exclusión social, son insuficientes para equilibrar los márgenes de actuación en el ámbito social entre las instancias estatal y europea, obstaculizando la construcción de un sistema de bienestar a nivel supranacional9 ${ }^{9}$.

En la segunda de las tesis expuestas, el programa de intervención normativa europea en el ámbito social habría sido lento y fragmentario, en consonancia con las dificultades que habría atravesado la integración económica

8 ALARCÓN CARACUEL, M.R., "La necessitá di un capitolo sociale nella futura Costituzione Europea" en Lavoro e Diritto, Vol 4. 2000, pp. 608-609.

${ }^{9}$ La división de competencias como origen del grave retraso que precede a la dimensión social respecto a la integración de los mercados ha sido puesta de relieve por AMATO, F., "La Carta dei diritti fondamentali dell'Unione e il lavoro flessibile: il valore della regola e l'interpretazione della giurisprudenza", en Rivista Giuridica del Lavoro e della Previdenza, n. ${ }^{\circ}$ 4, 2002 pp. 613-617. 
como estadio previo para la realización de la dimensión social. El instrumental promulgado durante los años sesenta y ochenta expresan este pausado avance social en la lucha contra la pobreza y la exclusión social. En concreto, los proyectos y programas comunitarios llevados a cabo por la Comunidad Europea entre 1975 y 1994, demostraron su inadecuación para convencer a los EEMM de la necesidad de aplicar a escala europea las medidas contenidas en los mismos. Las autoridades nacionales de entonces estaban más preocupadas por hacer frente a la nueva coyuntura económica internacional que exigía dejar a un lado la oleada de proteccionismo en el comercio europeo con el recurso a las ayudas estatales y las barreras técnicas al comercio. El tránsito de la construcción a la gestión del mercado comunitario marcaba la agenda política de la época, estando confinada la dimensión social al limbo de las resoluciones, recomendaciones y demás actos carentes de vinculación jurídica alguna. La tibieza normativa del Tratado de Ámsterdam que reconocía en su artículo 136 como objetivo de la Comunidad y los EEMM la lucha contra las exclusiones, evidenciaba la redundante subordinación de los objetivos sociales, y entre estos combatir la pobreza, a las exigencias del vínculo económico. De ahí que desde esta segunda propuesta se insistiera, al igual que en la anterior, en que las formulaciones empleadas para la dimensión social en los Tratados eran insuficientes. La apuesta por una redefinición de la integración positiva diferente a la contemplada por el Derecho originario, otorgaba de nuevo al espacio europeo un papel central en la formulación completa y sistemática de un dispositivo social supranacional ${ }^{10}$.

Desde estas bases, en nuestra opinión, resulta difícil abordar la temática dimensión social-Unión Europea. Su esterilidad radica en que la pérdida de la soberanía social nacional y la necesidad de sustituirla por otra, la soberanía social europea, que resuelva sus insuficiencias y contradicciones, deriva de una interpretación que neutraliza las transformaciones incorporadas por la nueva estructura constitucional europea. Ciertamente, estas reflexiones tenían cierta virtualidad en un contexto económico en el que la autonomía estatal para intervenir en el ámbito socio-económico era todavía factible, lo que atenuaba el impacto de la construcción del mercado único sobre los institutos estatales de redistribución. Aunque conviene recordar la importancia del elemento nuclear que define a la constitución económica comunitaria desde los Tratados fundacionales, el mercado como valor central y la subordinación de la dimensión social.

Pero, una vez infiltrados los postulados del constitucionalismo de mercado europeo en los derechos nacionales, en un principio y de manera pre-

10 ALARCÓN CARACUEL, M.R., "La necessitá di un capitolo sociale nella futura Costituzione europea", op.cit., pp. 612-613. 
ferente en el ámbito infraconstitucional y, posteriormente, con la conquista del mercado del tenor literal de los textos fundamentales a través de reformas que diluyen la dimensión garantista del Estado social, los sistemas constitucionales nacionales y europeo dejan de configurarse como dos realidades opuestas y autárquicas, en cuanto al tratamiento de sus respectivas dimensiones sociales, para fundirse en una misma realidad constitucional pergeñada en función del vínculo económico. De ahí que las demandas de construcción de un espacio social desde la instancia europea no puedan desvincularse de la naturaleza inherente al orden europeo. La introducción de medidas positivas concebidas como mecanismos correctores del déficit social supondría una intervención correctora en la esfera económica, un condicionamiento del mercado. Esta lógica vinculada al Estado social es ajena al ordenamiento europeo como proceso de afirmación de la centralidad y garantía del mercado ${ }^{11}$.

Por eso nuestra base de partida es distinta. Cuando decimos que la constitución económica europea introduce modificaciones sustanciales en relación con la constitución económica del Estado social, de tal forma que ambas resultan divergentes entre sí, ello nos obliga a analizar esencialmente tres aspectos. En primer lugar, identificar cuales son lo contenidos que definen uno y otro tipo de constitución, en un intento de elaboración global en referencia a ambos tipos de formulaciones. En segundo lugar, observar cómo se ha gestionado la crisis de la constitución económica europea para examinar si ésta ha supuesto una mutación del diseño normativo que la acompaña como sucedió con la crisis del constitucionalismo social, o bien ha significado una regeneración de contenidos sin alterar sus presupuestos más prístinos. En tercer lugar, determinar las implicaciones que conllevan estas cuestiones sobre la dimensión social europea en general, y la lucha contra la exclusión social en particular.

\subsection{La oposición entre las constituciones económicas del Estado social y de la Unión Europea}

\subsubsection{La consolidación del primado del mercado}

La identificación de la constitución económica europea con la preeminencia del mercado y los valores de los que es portador redefine el significado, el sentido, la estructura y morfología de los conceptos jurídicos del constitucionalismo social y, en especial, de su constitución económica. La

11 HATJE, A., "Wirtschaftsverfassung", en VON BOGDANDY, A. (coord.), Europäisches Verfassungsrecht, ed. Springer, Berlin-Heidelberg. 2003, p. 744. 
constitución económica del Estado social tiene su fundamento legitimador en la preeminencia normativa de las disposiciones referidas a la forma de Estado. Estas se traducen en la configuración del Estado social como la decisión constitucional fundamental que implica por una parte, una relación de funcionalidad a las disposiciones que articulan la constitución económica; y por otra parte, un vínculo social como fuente de definición y límite al mercado. El carácter prescriptivo de la constitución económica del Estado social deduce del complejo de principios constitucionales directamente vinculados a esta forma de Estado, un sistema de relaciones económicas caracterizadas por el primado de la política que se manifiesta en una serie de límites respecto a las libertades económicas privadas constitucionalmente reconocidas ${ }^{12}$.

Un dispositivo que habilita la intervención e introducción en el ámbito privado de una lógica distinta a la del capital y, supone la preeminencia de la política derivada del Estado social. Se trata de garantizar funcionalmente la conexión Estado-organización económica, instrumentada de manera que asegura la preeminencia del Estado para dirigir y modificar la organización económica. Por lo tanto, el modelo económico característico de la constitución económica del Estado social no se manifiesta en la convivencia de espacios público y privado vinculados al mercado, sino en el reconocimiento de la iniciativa privada en régimen de sustancial restricción o de subordinación a la dirección política del propio proceso económico. Con relación al segundo de los elementos de la constitución económica del Estado social, el vínculo social, se manifiesta en la definición normativa de los objetivos y límites de las actividades económicas. La funcionalidad de las libertades económicas está determinada por la utilidad social que se identifica con la tutela de las clases trabajadoras ${ }^{13}$.

La sustitución de estos presupuestos por otros, que son la traducción del proceso de integración económica europea y que se manifiestan como relevantes para su actuación, conforman a la constitución económica europea. Mecanismos como las libertades económicas, la GEE, instituciones como el Banco Central Europeo (BCE), e incluso el propio diseño del reparto competencial, se encuadran en un complejo normativo cuyo significado es tendente a consagrar al mercado como referente exclusivo y excluyente entre los socios europeos. De hecho, los redactores de los Tratados no formalizaron los contenidos del Estado social. Si en las constituciones de la segunda posguerra mundial se impusieron los contenidos

12 MAESTRO BUELGA, G., "Constitución económica y integración europea”, en Revista de Derecho Público, n. ${ }^{\circ}$ 54, 2002, pp. 33-112.

13 BAYLOS GRAU, A., "La contracción del Estado social", en Revista de Derecho Social, n. ${ }^{\circ} 63,2013$, pp. 20-22, y 25 . 
calificativos del Estado pluriclase, en el ordenamiento jurídico comunitario fueron las propuestas ordoliberales las que encontraron recepción normativa ${ }^{14}$. En éstas, las relaciones entre la política y la economía cambian. El Estado interviene, pero no en función del imperativo constitucional de la tutela social, sino del mercado y sus garantías. La intervención estatal sólo se produce cuando las condiciones del mercado ponen en peligro la competencia, que es la que define el espacio de poder político y su ámbito de realización. Desde esta perspectiva, se produce una funcionalidad de la política que invierte la relación entre economía y política propia del Estado social.

Cuestión distinta es la convivencia de dos constituciones económicas divergentes: la transnacional (inspirada en la economía social de mercado) y las constituciones económicas de los EEMM (vinculadas al constitucionalismo social), al menos hasta finales de la década de los ochenta cuando el proyecto político globalizador evidenció la necesidad de romper con el vínculo social del Estado social. La persistencia e incluso la expansión en algunos de los países miembros de sistemas caracterizados por penetrantes poderes de intervención en la economía, evidenciaron la necesidad de llevar a cabo la completa realización del mercado común y el progresivo acercamiento de las políticas económicas. El objetivo no podía ser simplemente dotar al ordenamiento comunitario de una legislación que eliminase los obstáculos al comercio intracomunitario, sino también realizar el mercado común en el verdadero sentido del término.

La experiencia de la integración inacabada había enseñado la indisolubilidad de ambos objetivos, mercado común e integración económica. La libre circulación de personas, servicios, capitales y mercancías se produce en virtud del principio de distribución óptima de los recursos, de los desplazamientos de la actividad económica bajo formas de nuevas localizaciones que, sin embargo, comportan por ellas mismas problemas económicos y sociales. La falta de una suficiente coordinación de las políticas económicas hacía que estos desplazamientos suscitaran tensiones y rupturas socio-económicas de tal magnitud, que las reacciones que pudieran conllevar en cada uno de los Estados amenazados ponía en peligro las libertades de circulación adquiridas.

La transición de la construcción a la gestión del mercado común europeo supone el fin de la constitución económica del Estado social y la puesta en escena de dos fundamentos inderogables. En primer lugar, la convicción de que una mayor coordinación de las políticas económicas no se podía ha-

14 JOERGES, C.H., “¿Qué tiene de social-demócrata la Constitución Económica Europea?”, en Revista española de derecho constitucional, n. . 73, 2005, pp. 9-53. 
cer depender de la buena voluntad de los países miembros cuyos gobiernos estaban sujetos a presiones internas y encontraban vínculos en las estructuras internas. En segundo lugar, la idea de que la convergencia horizontal de los sistemas nacionales no sucedería automáticamente como consecuencia de la integración de los mercados nacionales en el mercado común ${ }^{15}$. En el primero de los supuestos era necesario trasladar definitivamente los parámetros de la constitución económica comunitaria a las constituciones económicas de los EEMM o, lo que es lo mismo, privar a los gobiernos nacionales de todos aquellos poderes con los que pudieran modificar el curso natural del mercado Por el contrario, en el segundo supuesto sería necesaria la introducción de vínculos jurídicos o instrumentos de control en el espacio comunitario ${ }^{16}$. Estas líneas sintetizan y convergen en el máximo propósito del proyecto comunitario de finales de los ochenta: la Unión Económica y Monetaria (UEM).

Con Maastricht la disciplina macroeconómica entra en el constitucionalismo económico europeo desvinculando las políticas monetarias del cumplimiento de objetivos que expresen la intervención en la cohesión social. La prioridad de la estabilidad macroeconómica como mecanismo de tutela del sistema económico supone una fuerte constricción al espacio reservado a los EEMM en el ámbito económico y social. Con todo, la combinación de intergubernamentalismo y supranacionalismo de la eurozona consistente en la adopción de una política económica que refleja la tendencia intergubernamental, y la aplicación de una política monetaria vinculada al ámbito supranacional, se ha revelado como ineficaz para la contención de los desequilibrios macroeconómicos.

\subsubsection{Nueva gobernanza económica europea: de la crisis a la rehabilitación del vínculo económico}

La aceleración de los efectos la crisis financiera mundial en la eurozona condujo a un activismo de las instituciones europeas sin precedentes que se completó con la adopción de un conjunto de medidas destinadas a reforzar la arquitectura estructural de la GEE. Al respecto se ha señalado que las novedades registradas han comportado una importante dosis de intervención de las autoridades nacionales e instituciones europeas con la introducción de formas de gestión neokeynesianas, frente a las tradicionales respuestas

15 GUARINO, G., Eurosistema: analisi e prospettive, ed, Giuffré, Milán, 2006, pp. 8 y 35.

${ }^{16}$ Se trataría de vínculos jurídicos que tienen como objeto la estabilidad y la disciplina del balance, que se definen como los principios constituyentes de la economía social de mercado del Tratado de Maastricht. 
de gestión del vínculo económico ${ }^{17}$. Si bien, esta pretendida recuperación de un cierto dirigismo económico propio del Estado social queda en entredicho a tenor del objetivo marcado por el Consejo Europeo (CE) de marzo de 2010. Reforzar el marco jurídico de la GEE a través de un marco mejorado de resolución de la crisis y una mejor disciplina presupuestaria, se aleja claramente de la herencia del primado de la política del constitucionalismo social ${ }^{18}$. La preocupación por las distorsiones de la eurozona lejos de experimentar un cambio de objetivos, junto con la reducción de los macrodesequilibrios, un aumento de las tasas de empleo digno y de calidad y la reducción de la tasa de exclusión social, se ha concretado en reforzar los mecanismos de gobernanza económica ya existentes. Los riesgos no se interpretan como procedentes de los fallos del sistema financiero internacional, sino del propio diseño de la $\mathrm{UEM}^{19}$.

Las diferencias en la estructura administrativa de gobierno en la UE han proporcionado a los EEMM una capacidad de maniobra operativa que ha puesto en peligro el objetivo de la estabilidad monetaria. La Unión monetaria no puede ser efectiva en ausencia de una convergencia económica. De modo que las medidas a adoptar deben dirigirse con carácter preferente a conseguir una mayor disciplina presupuestaria y, una ampliación de la vigilancia económica a través de nuevos mecanismos. La vigilancia de la deuda pública como garantía de la estabilidad presupuestaria resume las coordenadas de la nueva GEE. Desde esta óptica, el nuevo modelo de GEE no supone una erosión del vínculo económico, sino la continuidad de la preeminencia de la integración negativa. La función del nuevo instrumental es controlar el comportamiento de los Estados con respecto a las condiciones de sanidad del sistema.

17 Estas propuestas consideran el modelo económico de la Unión adscrito a los postulados más prístinos del radicalismo hayekiano, a cuyo tenor, el elemento característico de la constitución económica europea habría sido la imposibilidad de las instituciones europeas de adoptar acciones incompatibles con las reglas abstractas de la competencia. De ahí que el rescate, tanto a instituciones financieras como a determinados países miembros, y las reformas de la GEE, impliquen una erosión del mercado socavando la eficacia de la economía perfecta. Las reducciones en el ámbito de aplicación del derecho de la competencia, en beneficio de medidas que muestran una mayor inclinación a preocupaciones típicas keynesianas respecto a cuestiones macroeconómicas, ilustran la nueva estrategia. En particular, se dirá que ahora hay mayores posibilidades para un gobierno keynesiano de la eurozona que antes de la crisis. La sola idea de que los desequilibrios macroeconómicos necesiten ser controlados y que los mercados no se auto-corrigen, es un eje central del keynesianismo. NICOLAS, J., "Re-problematizing neoliberalism", en Contemporary Political Theory, n. ${ }^{\circ}$ 4, 2013, p. 363.

18 HÄNNINEN, S., "Neoliberal politics of the Market", en No Foundation: an interdisciplinary Journal of Law and Justice, n. ${ }^{\circ}$ 10, 2013, pp. 43-45.

${ }^{19}$ COLLIGNON, S., "Europe's debt crisis, coordination failure and international effects”, ADBI Working Paper Series, n. ${ }^{\circ} 370$, julio 2012, pp. 24-25. 
A ello hay que añadir el revival por la búsqueda de la competencia perfecta o maximización de la competencia por parte de las autoridades nacionales, que además de actuar como mecanismo legitimador de la intervención estatal, lo hace como límite a una mayor intervención del Estado en la economía. La competencia define el espacio de intervención que es el mercado. La ausencia de mecanismos jurídicos vinculados a la dirección política del mercado interior en el espacio trasnacional que den una respuesta a la demanda de la distribución, traslada al ámbito social la lógica competencial. Esa es la finalidad de la nueva GEE, Pacto de Estabilidad y Crecimiento (PEC) mejorado ${ }^{20}$, Pacto Euro Plus ${ }^{21}$, Tratado de Estabilidad, Coordinación y Gobernanza de la Unión Económica y Monetaria (TECG) ${ }^{22}$,Tratado por el que se establece el Mecanismo Europeo de Estabilidad (MEDE) ${ }^{23}$, enca-

20 Paquete de seis medidas legislativas: Reglamento (UE) N. ${ }^{\circ}$ 1175/2011 del Parlamento Europeo y del Consejo de 16 de noviembre de 2011 por el que se modifica el Reglamento (CE) N. ${ }^{\circ}$ 1466/97 del Consejo, relativo al refuerzo de la supervisión de las situaciones presupuestarias y a la supervisión y coordinación de las políticas económicas (Diario Oficial L 306 de 23.11.2011, pp. 12-24). Reglamento (UE) N. ${ }^{\circ}$ 1177/2011 del Consejo de 8 de noviembre de 2011 por el que se modifica el Reglamento (CE) N. ${ }^{\circ}$ 1467/97, relativo a la aceleración y clarificación del procedimiento de déficit excesivo. Directiva 2011/85/UE del Consejo de 8 de noviembre de 2011 sobre los requisitos aplicables a los marcos presupuestarios de los Estados miembros. Diario Oficial L 306 de 23.11.2011, pp. 33-40. Reglamento (UE) N. ${ }^{\circ}$ 1174/2011 del Parlamento Europeo y del Consejo de 16 de noviembre de 2011, relativo a las medidas de ejecución destinadas a corregir los desequilibrios macroeconómicos excesivos en la zona del euro. Diario Oficial L 306 de 23.11.2011, pp. 8-11. Reglamento (UE) N.o 1173/2011 del Parlamento Europeo y del Consejo, de 16 de noviembre de 2011, sobre la ejecución efectiva de la supervisión presupuestaria en la zona del euro. Reglamento (UE) N. ${ }^{\circ}$ 1176/2011 del Parlamento Europeo y del Consejo de 16 de noviembre de 2011, relativo a la prevención y corrección de los desequilibrios macroeconómicos. Diario Oficial L 306 de 23.11.2011, pp. 1-7. Reglamento (UE) N. ${ }^{\circ} 1176 / 2011$ del Parlamento Europeo y del Consejo de 16 de noviembre de 2011, Diario Oficial L 306 de 23.11.2011, pp. 1-7.

Paquete de dos medidas legislativas: Reglamento (UE) N. ${ }^{\circ} 472 / 2013$, del Parlamento Europeo y del Consejo, de 21 de mayo de 2013, sobre el reforzamiento de la supervisión económica y presupuestaria de los Estados miembros de la zona euro cuya estabilidad financiera experimenta o corre riesgo de experimentar graves dificultades. Diario Oficial L 140 de 27.05.2013, pp. 1-10. Reglamento (UE) N. . 473/213, del Parlamento y del Consejo, de 21 de mayo de 2013, sobre disposiciones comunes para el seguimiento y la evaluación de los proyectos de planes presupuestarios y para la corrección del déficit excesivo de los Estados Miembros de la zona euro. Diario Oficial L 140 de 27.05.2013, pp. 11-23.

${ }^{21}$ Pacto por el Euro Plus. Refuerzo de la coordinación de la política económica a favor de la competitividad y la convergencia. Anexo I. Conclusiones del Consejo Europeo 24 y 25 de marzo de 2011, pp. 13-20.

22 Tratado de Estabilidad, Coordinación y Gobernanza en la Unión Económica y Monetaria (TECG), hecho en Bruselas el 2 de febrero de 2013, Boletín Oficial del Estado núm. 29, 2 de febrero de 2013.

${ }^{23}$ Tratado Constitutivo del Mecanismo Europeo de Estabilidad (MEDE), hecho en Bruselas el 2 de febrero de 2012. Boletín Oficial del Estado núm. 239, 4 de Octubre de 2012. 
minados a recuperar la confianza de los mercados a través de la juridificación de la austeridad permanente. La estabilidad presupuestaria como meta grundnorm en el código axiológico constitucional europeo y nacional. Esta filosofía de la estabilidad que acompaña a la UEM desde el Tratado de Maastricht, se ha visto reforzada con la crisis de gestión del eurosistema. La estrecha dependencia entre la estabilidad monetaria y la disciplina presupuestaria como condición indispensable para la salida de la crisis, ha conducido a una exaltación sin límites de la competencia que sólo puede alcanzarse a través del recurso a medidas de austeridad. Los EEMM y la propia Unión, vía mecanismos de vigilancia y supervisión macroeconómica, están obligados a evitar déficits públicos excesivos.

El control del déficit público junto con la estabilidad de precios, se articula en torno a una serie de vínculos de déficit presupuestario y mecanismos de supervisión macroeconómica de las finanzas públicas nacionales ex ante, que limitan el ámbito de las actividades de actuación de los EEMM y la UE. La sustancial limitación del ámbito de las decisiones discrecionales neutraliza la flexibilidad de las respuestas políticas y sociales nacionales y europeas a las oscilaciones económicas.

El cuestionable fortalecimiento de la competitividad en torno al cual se estructura la arquitectura institucional de la eurozona, de manera significativa en el Pacto Euro Plus, se configura a través de medidas de austeridad que buscan reducir draconianamente el gasto público para a la postre, bajar los niveles de endeudamiento. Los tibios síntomas de recuperación de algunos países de la periferia del sur de Europa no dejan de ser un espejismo que se ha materializado en un retroceso del bienestar a niveles de los años ochenta ${ }^{24}$. El latrocinio

${ }^{24}$ Corrobora esta afirmación, entre otros, el informe elaborado por la OIT (Organización Internacional del Trabajo), titulado "Informe mundial sobre salarios 2014/2015. Salarios y desigualdad de ingresos". De acuerdo con el documento, en Grecia y España el nivel del salario medio real en 2013 fue inferior al del año 2007 (página 16 del Informe). Asimismo, en España se ha producido un incremento de la desigualdad del $90 \%$ como consecuencia de las variaciones de la distribución salarial y la destrucción masiva de empleo (página 17 del informe).. A mayor abundamiento, las tipologías contractuales diseñadas por los legisladores griego y español para hacer frente al desempleo juvenil se han sustanciado en una disminución del salario de los jóvenes por debajo del umbral de la pobreza en Grecia, y en una mayor precarización de la relación laboral temporal en España. Al respecto, resulta significativo que según datos de Eurostat de 2014, en España el volumen de personas con contrato temporal que se encontraba en el año 2012 por debajo del umbral de la pobreza era del 16,2\%, mientras que en el caso de las personas con contrato indefinido era del 5,4\%. Con relación al caso griego vid: YANNAKOUROU, S. y TSIMPOUKIS, C.H., "Las reformas laborales en Grecia tras la crisis económica (2010-2012)", en Revista General del Trabajo y de la Seguridad Social, n. ${ }^{\circ} 34,2013$, pp. 16-19. Por lo que atañe a España destacan las siguientes medidas legislativas: Ley 11/2013, de medidas de apoyo al emprendedor y de estímulo del crecimiento y de la creación de empleo (Boletín Oficial del Estado, 27 de julio de 2013). Real Decreto-ley 
a la inversión en fines públicos tales como vivienda, educación, investigación, empleo y protección social, ponen de relieve no sólo los límites a los países miembros de la eurozona y las instituciones europeas en cuanto a las acciones a financiar, sino también al contingente presupuestario al pago de intereses sobre la deuda, en la querencia de que este presunto círculo virtuoso de competitividad-austeridad reducirá los intereses de la deuda y conducirá a la senda del crecimiento $^{25}$. Esta política económica y monetaria de talla única del eurosistema implica un examen de la crisis basado en el objetivo de finanzas sólidas y saneadas que se ha de imponer vía disciplina fiscal. Bajo tales condiciones, los Estados sólo pueden responder a través de medidas de recorte y reducción, cuando no supresión, de políticas de vínculo social. Este tipo de de-socialización o des-constitucionalización de los modelos de bienestar del Estado social, "han reducido de manera drástica los derechos económicos, sociales y culturales de la población creando pobreza, exclusión y aislamiento" 26 .

8/2014, de 4 de julio, de aprobación de medidas urgentes para el crecimiento, la competitividad y la eficiencia (Boletín Oficial del Estado, 5 de julio de 2014).

Desde esta óptica, el propio presidente del BCE, Mario Draghi, reconocía en septiembre de 2014 que en algunos países de la eurozona los salarios reales de quienes acceden al mercado de trabajo están a niveles de finales de los ochenta. Vid:http://www.ecb.europa.eu/press/ pressconf/2014/html/is140904.en.html (última consulta 08/06/2015).

${ }^{25}$ En este sentido son paradigmáticos por una parte, el Programa Nacional de Reformas 2012-2013, presentado por el Gobierno del Reino de España dentro del proceso del semestre europeo. En este programa la reducción en gasto social fue de gran calado, hasta el punto de que el presupuesto destinado al pago de la deuda en el año 2013, era casi igual a todo el gasto social. EAPN (The European Anti-Poverty Network), El impacto social de las políticas de austeridad, 2013, pp. 19-20.

Por otra parte, en el actual Programa Nacional de Reformas y su Programa de Estabilidad 2015 (Disponible en http://www.minhap.gob.es/es-es/prensa/en\%20portada/2015/ Paginas/20150430_CM.aspx, última consulta 08/06/2015), el gobierno contempla como mecanismos prioritarios para combatir la pobreza y la exclusión social, la creación de empleo y la inserción laboral vía programas de contratación que inciden de nuevo en la reducción de los costes empresariales por cotizaciones sociales (pp. 50-51 del Programa). La nueva medida de reducción de las cotizaciones a la Seguridad Social para fomentar la creación de empleo indefinido, continua la senda iniciada por la tarifa plana en el año 2014, y que se ha traducido en la práctica en un incremento del número de trabajadores pobres en España tal y como ha denunciado EAPN: "Spain: biggest rise in poverty since 2009, EAPN Spain proposes a Pact against Poverty to decision makers", http:/www.eapn.eu/en/news-and-publications/news/ eapn-national-networks-news/spain-biggest-rise-in-poverty-since-2009-eapn-spain-proposesa-pact-against-poverty-to-decision-makers, (última consulta 08/06/2015).

También resulta preocupante la insistencia del Programa en "racionalizar" el gasto e incrementar el ahorro en materia sanitaria, de educación, servicios sociales y recursos humanos (página 123 del Informe), propiciando el recurso a la privatización de servicios públicos esenciales para, precisamente, luchar contra la pobreza.

26 Proyecto de Informe sobre la situación de los derechos fundamentales en la Unión Europea (2013-2014) [2014/2254(INI)]. Comisión de Libertades Civiles, Justicia y Asuntos de Interior del Parlamento Europeo, considerando 17, página 8 del Informe. 
La elección de una Europa económica, frente a una Europa política y social, como garante del mercado distorsiona aquella otra lógica del primado de la política en la que se sitúan los sistemas de bienestar nacionales. La centralidad del vínculo económico determinante del imperativo constitucional europeo del mercado es el soporte desde el que se articulan las nuevas relaciones fruto del proyecto de integración europea. La apertura al intervencionismo estatal permite una ampliación del espacio público que se extiende a la política social, aunque siempre subordinada a la lógica del mercado al encontrar sus límites en la preservación de este último. De esta forma, las consideraciones que se realicen de la dimensión social en el contexto europeo están determinadas por la vigencia de modelo descrito.

\subsubsection{Funcionalidad de la integración positiva y solidaridad competitiva}

Desde la perspectiva descrita cobra todo su significado que el espacio social europeo se construyera desde sus orígenes, en clara funcionalidad a las exigencias de legitimación de un proyecto en el que devenía insostenible la introducción de mecanismos dirigidos a condicionar el mercado. En la relación integración positiva-intervención pública, desde la perspectiva de la constitución económica europea, la autonomía normativa de la dimensión social desaparece. Una economía de mercado abierta y de libre competencia no es aquella en la que el cálculo de costes y beneficios del funcionamiento de los mecanismos económicos está incorporado en la valoración de la eficiencia misma del sistema. La constitución económica europea actúa disciplinando a las constituciones económicas estatales a través de mecanismos de disolución de los ligámenes del constitucionalismo social. La política monetaria vincula a la política financiera de cada Estado Miembro. A su vez, la política financiera vincula a la política económica, y ésta a las políticas sociales. El balance entre exigencias económicas y necesidades sociales da como resultado un juicio económico consistente en valorar los costes económicos de la satisfacción de la pretensión ${ }^{27}$.

Paralelamente, aunque se ha señalado que el desfase entre los objetivos reconocidos en el modelo social europeo y las competencias institucionales de la Unión es un problema prioritario e ineludible que margina a la dimensión social europea a una situación de inactividad permanente, conviene hacer dos precisiones al respecto. Por un lado, la expresión modelo

27 ZUFIAUR NARVAIZA, J.M., "El modelo social europeo en la cuneta", en Revista Internacional de Filosofía Política, n. ${ }^{\circ}$ 31, 2013, pp. 101-122. ETXEZARRETA, M., "La evolución (perversa) de la política social de la Unión Europea”, en Revista Internacional de Filosofía Política, n. ${ }^{\circ}$ 31, 2013, pp. 123-138. 
social europeo constituye un significativo indicador de la posición de la política social europea en este mismo espacio. Sobre todo, porque no se trata de un espacio autónomo que se sitúa al mismo nivel que la integración económica, sino una mera dimensión de esta última con las características señaladas de subordinación y funcionalidad. Por otro lado, el supuesto desajuste entre objetivos sociales y la falta de instrumentos institucionales y de procedimientos decisorios dirigidos a hacerlos operativos en las relaciones intraeuropeas y en los ordenamientos nacionales, es coherente con el espacio residual y subalterno que la constitución económica europea reserva a la intervención pública en el mercado único.

El carácter accesorio, eventual y relegado a los espacios que expresan su compatibilidad con el mercado definen las nuevas bases, funcionales al espacio económico, y garantistas de los principios de la economía social de mercado, a las que se ve conminada la dinámica social europea. Ni la cohesión económica y social permite superar el carácter programático del dispositivo social y, por lo tanto, subordinado a los condicionantes macroeconómicos. La dimensión solidaria de la acción europea erosiona el carácter autónomo que el principio de la solidaridad exhibía en el Estado Social. Elemento vertebrador de las dinámicas de redistribución, ahora la solidaridad se privatiza a través del objetivo estratégico de la garantía del mercado interior ${ }^{28}$.

El objetivo, se dirá, no era el de sentar las bases para un futuro modelo social europeo, sino ofrecer una respuesta más realista a los desafíos de la competitividad y las tensiones entre los países miembros con distintos niveles sociales de protección ${ }^{29}$. A este argumento más específicamente defensivo se añade otro, más general y de carácter político-social. El espacio social europeo sirve para reforzar la identidad político-social europea en la medida en que promueve una mayor cooperación entre las instituciones públicas nacionales y supranacionales, favoreciendo un uso óptimo de los recursos humanos como uno de los factores más decisivos para la competitividad a escala mundial. La conclusión que se alcanza es que éste no estaría en contradicción con el nuevo paradigma europeo, sino que puede corresponderle en la medida en que favorece la movilización sobre objetivos comunes necesarios para Europa para hacer frente al turbulento contexto internacional. Precisamente, esta última afirmación, aunque formulada de manera un tanto ambigua, es la que nos proporciona las

28 BAYLOS GRAU, A., "Modelo social y políticas frente a la crisis", en Revista de Derecho Social, n. ${ }^{\circ}, 49,2010$, pp. 44-45.

${ }^{29}$ GIUGNI, G., "La dimensione sociale del mercato interno", en REGELSBERGER, E. y FERRARA, M (coord.), Italia e Germania protagoniste dell'integrazione europea, ed., Il Mulino. Bolonia. 1990, pp. 379-380. 
claves para entender el espacio reservado a lo social en el ordenamiento jurídico europeo.

En primer lugar, el término espacio social europeo pierde autonomía normativa desde el momento en que se hace viable en el espacio europeo desde una aproximación sustancialmente funcional, como dimensión vinculada al espacio económico y sus condicionantes. El refuerzo de las bases políticas y sociales aparece como algo secundario y, en todo caso, exclusivamente orientado a reforzar la posición de la UE en el contexto global de la mundialización. Los objetivos comunes se definen desde los condicionamientos de la competitividad, que aparece como el nexo de unión entre las instancias nacional y europea. Es ésta, y no la centralización a nivel supranacional de la protección social como respuesta a la erosión de los sistemas nacionales de welfare, el vínculo que conecta lo social con la competencia desde una doble perspectiva. Por una parte, la dimensión social se define como espacio subordinado a las exigencias del mercado y de la competencia. Por otra parte, la competencia y el mercado interior determinan los nuevos espacios de la dimensión social europea, caracterizados por su compatibilidad subalterna con los contenidos de la integración negativa.

En segundo lugar, la sustitución de la armonización por técnicas débiles carentes de vinculación normativa (MAC) es paralela al incremento de competencias comunitarias en el ámbito social. A medida que el nivel europeo gana espacios de intervención en el ámbito social, éstos se redefinen desde el ámbito supranacional de acuerdo con el principio metaconstitucional de la economía abierta y de libre competencia, donde la formulación de gobierno débil-control fuerte adquiere toda su fuerza expresiva. Fundamentalmente, porque la ratio justificativa de la intervención social europea no es la creación de un ámbito propio de regulación social, sino la de controlar que los sistemas nacionales no adopten medidas que puedan suponer la puesta en peligro del mercado interior europeo. Una intervención que se confirma funcional a las nuevas posibilidades que se abren para la maximización de la competencia ${ }^{30}$.

En tercer lugar, la definición de los niveles mínimos de protección desde el ámbito interno y no desde la propia Unión supone la garantía de mayores márgenes de flexibilidad que favorecen la competencia entre regulaciones. Sancionando la transferencia de la competencia a lo social. Se trata de una renuncia coherente con los espacios de intervención que definen la competencia como principio constitutivo de la garantía del mercado interior.

30 SOMMA, A., "Tutte le strade portano a Fiume. L'involuzione liberalista del diritto comunitario", en Rivista critica del diritto privato. Vol. 20, n. 2,. 2002, pp 263-286. 
Este déficit de tutela del Derecho de la Unión se manifiesta sobremanera en la tensión entre Solidaridad e integración negativa. Se ha señalado que la Carta de Derechos Fundamentales de la Unión Europea (CDFUE) responde a los intentos de acabar con los desequilibrios generados por la asimétrica integración negativa a través de la reunificación en un catálogo específico y propio para la UE de aquellos valores y derechos asumidos como fundamentales y, que constituirían, al mismo tiempo, el soporte de legitimidad del ordenamiento europeo ${ }^{31}$. En esta nueva perspectiva de superación de los límites funcionales establecidos en los Tratados, la Carta afirma la indivisibilidad e interdependencia de los derechos de la primera, segunda y tercera generación, en torno a la dignidad de la persona como axioma central y aglutinante ${ }^{32}$. Los derechos civiles, políticos, económicos y también sociales, son derechos con un estatus igual al de las libertades económicas.

A pesar de las expectativas creadas por esta presunta recomposición de los valores europeos, a nuestro parecer, la Carta lejos de establecer una relación simbiótica entre integración negativa y positiva, perpetua la asimetría. Conforme al modelo normativo y material del constitucionalismo económico, en la CDFUE se asume como irrelevante la desigualdad socio-económica, mientras que se fortalecen las pretensiones del atomismo individualista en una línea de ruptura y regresión del constitucionalismo social. "Por esto, expresa una cultura jurídica de los derechos que parece más atenta a proteger esferas de identidad personal de las amenazas que trae consigo el desarrollo científico y tecnológico, que a poner muros de contención a los riesgos conexos a las nuevas causas de inseguridad de la sociedad europea; una cultura más sensible a los derechos relativos a la calidad de vida que a la remoción de los desequilibrios económico-sociales" 33 .

En el constitucionalismo de mercado la competencia actúa privatizando el espacio de realización del bienestar social, redefiniendo los valores que permitían la intervención pública en el sistema económico a través de la actuación de políticas de tipo redistributivo. La captación de lo social por el mercado desocializa y mercantiliza a la solidaridad. Una solidaridad desarmada en la medida en que se hace depender del mercado su efectiva realización. La falta de disposiciones adecuadas que supongan un reforzamiento

31 MANZELLA, A., "Dal mercato ai diritti" en Riscrivere i diritti in Europa. Introduzione alla Carta dei diritti fondamentali dell'Unione Europea, Bolonia, 2001, pp. 29-31.

${ }^{32}$ MANZELLA, A., "Dal mercato ai diritti", en Riscrivere i diritti in Europa. Introduzione alla Carta dei diritti fondamentali dell'Unione Europea, ed. Il Mulino, Bolonia. 2001, pp. 29-31. RODOTÁ, S., "La Carta come atto politico e documento giuridico", en Riscrivere $i$ diritti in Europa. La Carta dei diritti fondamentali dell'Unione Europea, AAVV, Ed. Il Mulino. Bolonia. 2001, p. 74.

${ }^{33}$ GRECO, R., "Il modello sociale della Carta di Nizza", en Rivista giuridica del Lavoro e della Previdenza Sociale, n. ${ }^{\circ} 3.2006$, pp. 519 y ss. 
de los derechos previstos en el capítulo cuarto de la Carta informados por el componente axial de la solidaridad, afianza las conclusiones apuntadas. En particular, el empleo en el párrafo tercero del artículo 34, donde se contempla el derecho a una ayuda social y a una ayuda de vivienda para combatir la exclusión social y la pobreza, de la expresión "la Unión reconoce y respeta", supone una redacción menos elaborada que acusa la pérdida, en la dimensión constitucional, de la dinámica garantista de los sistemas de bienestar herederos del constitucionalismo social.

\section{Traducción político-normativa de la lucha contra la pobreza}

\subsection{La exclusión en el marco de la política social en el Tratado de Lisboa}

Contextualizadas las bases materiales del constitucionalismo de mercado europeo en torno a la preeminencia del mercado y el vínculo económico como tutela-garantía de sus condicionantes, su modelo social se configura desde las coordenadas de la falta de correspondencia entre la esfera del mercado interior y el poder público europeo que prescribe la economía social de mercado. Por eso, en el artículo 3.3 del Tratado de la Unión (TUE), al momento definidor del modelo social europeo, representado por la economía social de mercado, se yuxtapone una desordenada alusión al empleo y al progreso social, a un nivel elevado de protección y mejora de la calidad del medio ambiente. Y todo ello desnaturalizado a su vez, por la alusión a la alta competitividad que termina por reconducir su materialización normativa a la pura economía de mercado, en sintonía con el modelo de constitución económica vigente desde los inicios del proyecto. La aparente sustitución de las formas de integración negativa por otras de integración positiva en el Tratado de Lisboa se relativizan. Los objetivos sociales formulados por el artículo 3.3, combatir la exclusión social, fomentar la justicia y la protección social, la cohesión económica y social, se sitúan en un marco de compatibilidad con otros objetivos, UEM, que comprometen su estatus en el ordenamiento jurídico europeo al ser incapaces de actuar como límites al mercado $^{34}$.

Tampoco la introducción de la cláusula horizontal social del artículo 9 del Tratado de Funcionamiento de la Unión Europea (TFUE), ha supuesto una innovación real de alcance constitucional que actúe comprometiendo el modelo descrito. Aunque se establezca que en la ejecución de sus polí-

${ }^{34}$ LASA LÓPEZ, A., Los derechos sociales en el constitucionalismo de mercado: aporías de la dimensión social en la Unión Europea, ed. Servicio Editorial de la Universidad del País Vasco, 2012, pp. 113 y ss. 
ticas y acciones, la Unión tendrá en cuenta las exigencias relacionadas, entre otras, con la lucha contra la exclusión social, éstas han de modularse con las necesarias condiciones de flexibilidad para que no acaben representando un obstáculo para la garantía del mercado interior. El rango preeminente de la economía de mercado abierta y de libre competencia en el catálogo de los valores del Derecho de la Unión, actúa como límite y garantía del proceso europeo.

Paradigmático en este sentido es el fundamento jurídico de la lucha contra las exclusiones, y por lo tanto, contra la pobreza, esto es, el artículo 151 del TFUE. La Unión y los EEMM para alcanzar el objetivo de la erradicación de la pobreza "tendrán presentes", los derechos sociales fundamentales como los que se indican en la Carta Social Europea, firmada en Turín el 18 de octubre de 1961, y en la Carta Comunitaria de los derechos sociales fundamentales de los trabajadores de 1989. La explícita referencia a los derechos sociales fundamentales reconocidos en la CSE y en la CCDSF no va más allá de una ilusión óptica por conseguir un mayor equilibrio entre los valores económicos y sociales. Por lo pronto, es significativo que el Tratado de Lisboa mantenga el antiguo 136 del Tratado de la Comunidad Europea, que reconduce a la Unión al primer estadio del ciclo evolutivo de los derechos de Marshall, contradiciendo el garantismo normativo del constitucionalismo social. Además, el ingreso en el patrimonio normativo europeo de los derechos sociales reconocidos en las Cartas sociales de 1961 y 1989 , es cuanto menos dudoso. Del tenor literal del artículo 151 se observa como el contenido de ambas Cartas no es interiorizado por el Tratado, "teniendo presentes", sino que se adopta la técnica del reenvío a los textos.

Pero la posición de subordinación a los objetivos económicos de la unión monetaria en la que se colocan los objetivos de la política social en la jerarquía global de los fines de la Unión, es especialmente visible en los apartados segundo y tercero del artículo 151 del TFUE. En la cima de la jerarquía de los fines se sitúa la política económica guiada por los cánones de la unión monetaria: control de la inflación y de la deuda pública. De ahí que la política social deba hacer las cuentas con "la necesidad de mantener la competitividad de la economía de la Unión (art. 151 pfo. $2^{\circ}{ }^{\circ}$ ). Y además, que los distintos objetivos sociales contemplados por el artículo 151 serán obtenidos en primer lugar, "del funcionamiento del mercado interior, que favorecerá la armonización de los sistemas sociales". De tal forma que la política social europea está sujeta a un balance desigual con las exigencias monetarias de eficiencia económica y estabilidad presupuestaria, donde el medio para su realización, finanzas públicas saneadas, no sólo está en un nivel jerárquico superior al fin social, sino que además determina su alcance jurídico real. 
El complejo de esta disposición indica que los derechos sociales necesarios para combatir la exclusión social no son un límite absoluto, tampoco una finalidad de la acción de la Unión y de los países miembros que se limitan a "tenerlos presentes". Lo que realmente obliga a la Unión y a los EEMM son los intereses sociales presentados en forma de objetivos (empleabilidad, protección social, diálogo social, etc.) y son estos el objeto de tutela por parte del Tratado (que es la ley fundamental de la Unión). En cambio, los derechos sociales permanecen como fuentes de inspiración, y la oportunidad de su satisfacción está conectada a la necesidad de la realización de los objetivos sociales. Los derechos sociales en el ordenamiento jurídico europeo retornan a un estado de Reflexrechte ${ }^{35}$.

\subsection{Carta Social Europea, Carta Comunitaria de los Derechos}

Sociales Fundamentales de los Trabajadores, Carta de Derechos

Fundamentales de la Unión Europea: alcance y garantías del derecho a la protección contra la pobreza

La Carta Social Europea adoptada por los Estados miembros en el Consejo de Europa en Turín en 1961, y posteriormente revisada en 1996, tiene como contenido exclusivo un amplio elenco de derechos sociales [derecho al trabajo - art. 1-, libertad sindical - art. 5-, negociación colectiva - art. 6-, derecho de los niños y adolescentes a la protección en el trabajo - art. 7-, derecho a la seguridad social - art. 12-, a la asistencia social y médica - art. 13-, a la protección social, jurídica y económica de la familia - art. 16-, el derecho a la protección y a la asistencia de los trabajadores migrantes y sus familias - art. 19- igualdad de oportunidades en materia de empleo y profesiones sin discriminación por sexo - art. 20-]. En la Carta los Estados se obligan a un número determinado de disposiciones que no pueden ser inferiores a 16 artículos o 63 párrafos numerados, y que ellos mismos pueden elegir. Por lo tanto, la Carta es obligatoria para los Estados que la suscriben sólo parcialmente y no en su totalidad. Además, esta vinculación parcial es designada no por la Carta sino por los Estados que la asumen. Junto a esta ratificación "a la carta", es importante poner de relieve que la exclusión social no figuraba entre el elenco de derechos sociales contemplados por la CSE original, y que no será hasta su revisión en el año 1996, cuando la protección contra pobreza y la exclusión social se incluya como nuevo derecho social (artículo 30 de la CSE revisada). Si bien, dentro

${ }^{35}$ LUCIANI, M., "Diritti sociali e integrazione europea", en Politica del Diritto, n. ${ }^{\circ} 3$, 2000, p. 372. 
del "núcleo duro" de derechos sociales de la CSE revisada que los Estados deben aceptar necesariamente, no figura la disposición relativa a la exclusión social.

Pese a esta última observación, el Derecho de la Unión únicamente alude a la CSE original que, como se acaba de señalar, no incluía la garantía de la protección contra la pobreza como derecho, lo que minimiza la repercusión jurídica de este documento internacional en la lucha contra las exclusiones por parte de las instituciones europeas. A ello habría que añadir la ausencia de una adhesión de la UE a la CSE similar a la adhesión al Convenio Europeo para la Protección de los Derechos Humanos y de las Libertades Fundamentales (CEDH), que contempla el artículo 6.2 del TUE. Situación que profundiza, a nuestro parecer, el estatus marginal de los derechos sociales. En primer lugar, por la propia caracterización que de estos derechos se efectúa por el ordenamiento europeo. En segundo lugar, porque aunque pudiera parecer que la referencia a los derechos humanos sugiere que dentro de los mismos se incluyen los derechos sociales, la realidad jurídica no autoriza tal conclusión. Teniendo en cuenta que el TUE interpreta tal fórmula acorde con el CEDH, haciendo coincidir los derechos del hombre con las libertades fundamentales, se impone la conclusión de la imposibilidad de articular derechos sociales fundamentales en base al instrumento de la Convención. De las consideraciones efectuadas se desprende que la Carta original dista de ser una fuente de legalidad en el derecho comunitario europeo.

Por su parte, la CCDSF fue adoptada en la reunión del Consejo Europeo celebrado en Estrasburgo en diciembre de 1989. Aunque desde un sector de la doctrina se le ha reconocido una cierta eficacia fáctica, con visos de futura virtualidad jurídica, condicionada a su inserción en las fuentes comuni$\operatorname{tarias}^{36}$, lo que sí es constatable es la imposibilidad de la justiciabilidad de los derechos sociales proclamados por la Carta, lo que ha conducido a cuestionar la utilización de la propia noción de derechos fundamentales ${ }^{37}$. Esta falta de garantía jurídica se manifiesta claramente con respecto a sus mecanismos de aplicación. Conforme al artículo 27 "la garantía de los derechos sociales fundamentales de la presente Carta, así como la aplicación de las medidas indispensables para el buen funcionamiento del mercado interior en el marco de una estrategia de cohesión económica y social, competen a los Estados miembros de conformidad con las respectivas prácticas nacionales, en particular mediante su legislación y convenios colectivos”. Por lo

${ }^{36}$ LA MACCHIA, C., "La Carta comunitaria dei diritti sociali", en Giornale dei diritto del lavoro e di relazioni industriale, n. $^{\circ}$ 48, 1990, p. 787.

37 MONEREO PÉREZ, J. L., "Carta comunitaria y derechos sociales fundamentales de los trabajadores", en Civitas. Revista española de derecho del trabajo, n. ${ }^{\circ}$ 57, 1993, pp. 7578. 
tanto, el contenido de la Carta no es interiorizado por los ordenamientos internos, situándose en la estela de texto inspirador.

A continuación, el artículo 28 condiciona la aplicación efectiva de la Carta a la adopción de instrumentos jurídicos, si bien las instituciones europeas únicamente podrán legislar en relación a aquellos derechos previstos en el marco de competencias de la Unión definidas por los Tratados. No hay por lo tanto ampliación de competencia alguna a favor de la Unión en materia de derechos sociales. En cuanto a los mecanismos de control previstos en los artículos 29 y 30, lógicamente estos carecerán de naturaleza jurisdiccional dada la no obligatoriedad jurídica de la Carta. De hecho, este control consiste en la elaboración por la Comisión de un informe anual sobre la aplicación de la Carta por los EEMM y la Unión, que será trasmitido al Consejo Europeo, al PE y al Comité Económico y Social ${ }^{38}$. Con respecto a su contenido, destaca la heterogeneidad de la Carta combinando derechos ${ }^{39}$ con recomendaciones ${ }^{40}$, lo que propicia de alguna manera la divisibilidad de la sistemática, dada la tipología por ella establecida. En este sentido, la naturaleza meramente promocional de los derechos sociales que tiene la CCDSF, la convierten en un instrumento poco idóneo para garantizar la protección jurídica de los derechos sociales fundamentales en el ordenamiento europeo ${ }^{41} \mathrm{y}$, especialmente, del derecho de las personas que estén excluidas del mercado de trabajo a beneficiarse de prestaciones y recursos suficientes adaptados a su situación personal (art. 10 párrafo segundo de la CCDSF).

La situación normativa del derecho a la protección contra la pobreza y la exclusión social no cambia mucho si acudimos al texto de Niza. El derecho se contempla en el Capítulo IV, titulado Solidaridad, en la CDFUE. Las valoraciones que hemos efectuado a propósito de la Solidaridad y su configuración en el ámbito supranacional, son el soporte desde el que el fundamentar la caracterización funcional al paradigma de mercado que

38 Desde esta perspectiva es significativo el Dictamen emitido por el Comité Económico y Social de la Comunidad Europea el 22 de febrero de 1989, donde se ponía de relieve, como conclusión final, la importancia que tiene para el Comité el no calificar jurídicamente los instrumentos que asegurarán las garantías sociales de los ciudadanos europeos mediante una terminología derivada del derecho internacional clásico, como Carta o Convenio, por cuanto ello significaría considerar a la política social comunitaria como un interés secundario en la realización del mercado interior.

39 "Asociarse libremente para constituir asociaciones profesionales o sindicales" (punto 11.1) o "beneficiarse gratuitamente de los servicios públicos de colocación" (punto 6).

40 "Conviene intensificar las acciones destinadas a garantizar la realización de la igualdad entre hombres y mujeres" (punto 16) o "deben adoptarse las medidas necesarias para adecuar las normas del derecho del trabajo aplicables a los jóvenes trabajadores, de manera que satisfagan las exigencias de su desarrollo y las necesidades de su formación profesional" (punto 22).

${ }^{41}$ MONEREO PÉREZ, J. L., "Carta comunitaria y derechos sociales fundamentales de los trabajadores", op. cit, pp. 78 y ss. 
la exclusión social recibe en este documento. En particular, el proceso de constitucionalización de los derechos sociales fundamentales en el espacio europeo se ha caracterizado por el objetivo predominante de la integración económica. De ahí que la garantía del principio de solidaridad se sustancie, en lo fundamental, en una compatibilidad subalterna con el mercado que se contagia a aquellos derechos que tienen en ella su fuente directa de inspiración. La consecuencia directa de ello es que el carácter funcional de la solidaridad a los principios prescriptivos de la constitución económica europea ha excluido la positivación del vínculo social. Esta funcionalidad está presente en los estándares y técnicas de tutela previstas en la disposición de la Carta que contempla la exclusión social.

Concretamente, en el apartado tercero del artículo 34 se establece: "Con el fin de combatir la exclusión social y la pobreza, la Unión reconoce y respeta el derecho a una ayuda social y a una ayuda de vivienda para garantizar una existencia digna a todos aquellos que no dispongan de recursos suficientes, según las modalidades establecidas por el Derecho de la Unión y por las legislaciones y prácticas nacionales". La sistemática de la disposición se caracteriza por la indeterminación de los estándares sustanciales de tutela de las ayudas previstas, acentuando el margen de discrecionalidad de la fuente legislativa como espacio de materialización de los derechos a ayudas sociales contemplados por la norma. El reenvío genérico a la legislación nacional y europea sitúa en estos ámbitos la fuente directa de la lucha contra la exclusión social y sus garantías, marginando a la CDFUE como marco de referencia de la garantía constitucional de los derechos. Precisamente, es en estos espacios donde asistimos en las últimas décadas a la materialización de las transformaciones que tienen una vinculación directa con los parámetros del constitucionalismo de mercado. Las reformas en los sistemas de bienestar estatales tienen lugar en un contexto caracterizado por la crisis financiera internacional y las disposiciones legislativas de la nueva GEE. Las respuestas a estas dinámicas no se efectúan desde la óptica de la reserva de competencia del vínculo social frente a la interferencia del vínculo económico, sino desde la perspectiva de la subordinación de los contenidos sociales a las prerrogativas de la integración negativa.

\subsection{La Estrategia Europa 2020}

Se presenta como una iniciativa de la Comisión que sucede a la Agenda de Lisboa ${ }^{42}$, y cuyo objetivo es conseguir un crecimiento inteligente, soste-

42 Conclusiones del Consejo Europeo de 23 y 24 de marzo de 2000 reunido en la ciudad de Lisboa (Agenda Lisboa). 
nible e integrador. Se trata de un documento político gestado en plena crisis que busca consolidar una estrategia "creíble de salida de la crisis" a través de la superación de los instrumentos políticos como respuesta tradicional para contrarrestar la crisis, y la articulación de un enfoque coordinado consistente en tres prioridades: 1) Un crecimiento inteligente basado en el desarrollo de una economía basada en el conocimiento y la innovación. 2) Un crecimiento sostenible de promoción de una economía que utilice más eficazmente los recursos, que sea verde y competitiva. 3) Un crecimiento integrador que fomente una economía con un alto nivel de empleo que redunde en la cohesión económica, social y territorial ${ }^{43}$. La lucha contra la pobreza y la exclusión social se integra dentro de este tercer pilar que contempla como iniciativa emblemática la Plataforma Europea contra la Pobreza ${ }^{44}$. El enfoque proactivo de la Comisión en la lucha contra la exclusión social se sustancia a escala europea en la transformación del método abierto de coordinación sobre exclusión y protección social en una plataforma de cooperación, en el diseño y aplicación de programas de promoción de la innovación social para los más vulnerables, así como en buscar el equilibrio entre la viabilidad y la mejora de los sistemas de protección social y pensiones. Como acción clave para valorar la traducción de los objetivos descritos en las políticas nacionales, destaca la supervisión de las reformas económicas y estructurales de los países miembros a través del Semestre Europeo.

A la vista del enfoque social de Europa 2020, pudiera parecer que la lucha contra la exclusión social adquiere con esta estrategia la consideración de verdadero objetivo cuantificable en términos no sólo políticos, sino también jurídicos, dadas las medidas señaladas por la Comisión para alcanzar "la meta común de que la Unión Europa saque por lo menos a 20 millones de personas de la pobreza y la exclusión social en la próxima década". Empero, la inadecuación de objetivos y mecanismos para su adopción se desprende con claridad tanto de las medidas como de sus campos de acción.

La respuesta institucional de la UE a la crisis mantiene el paradigma descrito de la intervención reguladora, a saber, autonomía del mercado y compatibilidad subalterna de la política social. La economía de mercado sigue siendo el punto de partida para la salida de la crisis, tal y como se pone de relieve en la consulta pública sobre la estrategia "UE 2020". La recuperación continua confiándose al mercado y su principal valedor, la competencia. Todo ello a pesar de que la crisis ha desvelado las carencias del modelo económico adoptado por el constitucionalismo de mercado de la Unión. Sobre todo, la ausencia de un gobierno económico europeo que dote

${ }^{43}$ Op. cit., nota 3, pp. 7, 22, 24 y 37.

44 Op. cit., nota 4, pp. 6-20. 
a la Unión de competencias de gestión y de intervención. De tal forma que la constitución económica europea continúa depositando su confianza en el mercado y la regulación como mecanismo de tutela. Sólo bajo este dogma puede entenderse la contextualización de la lucha contra la exclusión social en el ámbito del Semestre Europeo, que no es sino un mecanismo adicional para ejercer un control del cumplimiento de las condiciones del constitucionalismo de mercado europeo por las finanzas públicas nacionales, y donde las consideraciones sociales sobre pobreza y exclusión social están muy lejos de colocarse al mismo nivel que las condiciones macroeconómicas.

A mayor abundamiento, en el Estudio Prospectivo Anual sobre el Crecimiento para $2015^{45}$, donde la Comisión esboza los principales aspectos de su nueva agenda a favor del crecimiento y del empleo, no hay una sola referencia a mejorar la lucha contra la exclusión social, y las medidas llamadas a profundizar en la dirección apuntada por el tercer objetivo estratégico de Europa 2020 se adoptan bajo los parámetros de la falta de autonomía de la dimensión social europea. La Comisión considera necesario adoptar un enfoque integrado que combine las políticas estructurales, presupuestarias y monetarias reforzando la panoplia de la nueva GEE. Principalmente, se señala que "ha llegado el momento de racionalizar y reforzar el Semestre Europeo para dotarlo de mayor eficacia. Un Semestre Europeo reformado debe perseguir la eficacia de la coordinación de la política económica a escala de la UE" (página 18). La racionalización del sistema de gobernanza europea para aumentar su eficacia y acrecentar el sentimiento de apropiación político de la gobernanza económica de la UE, implica una revisión del paquete de seis y el paquete de dos medidas legislativas que persevere en la responsabilidad presupuestaria a través de un saneamiento presupuestario responsable y favorable al crecimiento.

En paralelo, la dimensión integral del informe se completa con la apuesta por reformas estructurales a escala de los EEMM que lejos de rozar tangencialmente la integración positiva, redundan en su carácter marginal. Concretamente, mejora de la dinámica de los mercados laborales y medidas frente al elevado nivel de desempleo (pp. 13-14), reforma de las pensiones (p. 14), y modernización de los sistemas de protección social (p. 14). Empleando expresiones tales como "evolución salarial acorde con la productividad", "reforma de litigios en el ámbito laboral" o "enfoque dinámico de la edad a la cual las personas deben jubilarse", se trata de funcionalizar las políticas sociales y de empleo nacionales a las exigencias de la competitivi-

45 Comunicación de la Comisión al Parlamento Europeo, al Consejo, al Banco Central Europeo, al Comité Económico y Social Europeo, al Comité de las Regiones y al Banco Europeo de Inversiones. Estudio Prospectivo Anual sobre el Crecimiento para el 2015, Bruselas, 28.11.2014. COM (2014) 902 final. 
dad. El hecho de que la referencia expresa a los sistemas de protección social se haga bajo el rótulo "modernizar", supone sancionar la vinculación entre modernización de los sistemas de bienestar nacionales y solidaridad competitiva, como si actuase una superposición entre los dos términos con coincidencia de extremos semánticos. Frente a la reforma de los sistemas de protección y de seguridad social de los derechos internos desconectados del análisis de su impacto social restrictivo, lo acertado en términos de Europa social y política, o si se prefiere, de acrecentamiento del sentimiento de apropiación a nivel europeo de una dimensión social garantista, hubiera sido incrementar las expectativas reales de realización y puesta en práctica del derecho social fundamental a una protección social efectiva como principal aval para combatir la exclusión social y su poliédrica dimensión.

\section{Conclusiones finales}

\subsection{La vacuidad de las aportaciones basadas en la regeneración social del Derecho de la Unión}

El déficit de la dimensión social europea es una constante rastreable en la literatura jurídica que analiza la materia. Pero, las diferencias surgen a la hora de determinar las causas del mayor o menor grado de interiorización de funciones sociales por la Unión, el nivel de acción de las políticas sociales en cada uno de los niveles, el estatal y el europeo, así como la interacción entre ambos. Desde estas coordenadas, se pueden distinguir dos perspectivas en la aproximación a la organización del modelo social del constitucionalismo de mercado europeo. Ambas tienen en común vincular el déficit del modelo social europeo a las renuencias de los EEMM a transferir el ejercicio de competencias en ámbitos tan sensibles, desde el punto de vista de captación de votos, como la seguridad social o los servicios públicos.

Una primera perspectiva consistiría en poner de relieve los desequilibrios entre integración negativa y positiva desde la perspectiva de localizar la actividad de la integración positiva en el ámbito estatal, en detrimento del espacio europeo que aparecería vinculado casi en exclusiva a la integración negativa. Se trata de dos espacios independientes, sin que uno u otro interactúen entre si. De aquí que consideremos que esta tesis resulte forzada. En primer lugar porque el constitucionalismo de mercado europeo acentúa los caracteres de la centralidad del mercado y la funcionalidad de la intervención pública al pleno desarrollo de ésta. En esta tesitura, la integración positiva resulta funcional en sus relaciones a la lógica económica. La retirada de los vínculos del Estado social obliga a redefinir la intervención desde el 
espacio europeo y, por lo tanto, es el ordenamiento europeo el que impone una nueva forma de intervención en los nuevos espacios social y económico que se abren a la competencia. El objetivo es la garantía del sistema institucionalizado en la UE-GE mejorada y mercado interior. Las autoridades estatales complementan el marco de garantías del mercado dado que los intereses tutelados por los gobiernos nacionales se construyen desde los condicionantes del mercado, actuando la sustitución del gobierno político de la economía por la autonomía del mercado. La heterocorreción como funcionalidad de la política, permeabiliza al conjunto de las relaciones sociales y se convierte en el paradigma de la constitución económica europea. Es el vínculo económico el que acaba trasladando sus contenidos al espacio de las Constituciones nacionales. De ahí que no tenga mucho sentido descargar la responsabilidad de la ausencia de un espacio social europeo en el mantenimiento de las prerrogativas sociales nacionales ${ }^{46}$.

Por otro lado, si la política social es considerada como un mecanismo vital de redistribución social en el Estado social, entonces tenemos que decir, en consonancia con los argumentos expuestos a lo largo de estas páginas, que tal política social no existe en el ordenamiento europeo. Es necesario redefinir estas políticas sociales de la integración negativa desde la perspectiva del modelo social que se articula en los Tratados. Como se ha puesto de relieve, las competencias que dan actuación al modelo social de los Tratados se articulan, fundamentalmente, a través de competencias residuales que no buscan corregir sino ser funcionales al mercado. En este sentido, las políticas de regulación comunitaria derivan de una base filosófica diferente de las tradicionales políticas sociales ${ }^{47}$.

El carácter marginal está en clara correspondencia con la centralidad del mercado frente a la subordinación del vínculo social. "La economía como política social, donde ésta no sólo se subordina a aquella, sino que se realiza en su interior. Los ámbitos de intervención tienen que ver con la mejora de la competitividad de los capitales nacionales, sólo que estas actúan sobre los ciudadanos en su inserción en el mercado. El cambio de modelo significa el tránsito de la solidaridad redistributiva - correctora del mercado - a la solidaridad competitiva. La distribución no es ya el campo de acción de la política social, porque redistribuir significa corregir, no sólo expost, la actuación del mercado y por ello actuar sobre la competencia"48.

46 WALBY, S., "The new regulatory State: the social powers of the European Union" en British Journal of Sociology. Vol. 50, n. ${ }^{\circ}$ 1, 1999, pp. 129-136.

47 MAJONE, G., "The European Community between social policy and social regulation”, en Collected Courses of the Academy of European Law, Vol. 1, 1994, pp. 321-419.

48 STREECK, W., "Il modelo sociale europeo: dalla redistribuzione alla solidarietá competitiva", en Stato e mercato, n. ${ }^{\circ} 1,2000$, p. 14. 
Desde esta perspectiva es desde la que debe analizarse las implicaciones de las políticas sociales europeas.

La segunda de las lecturas aunque también parte de la base de que el modelo social europeo es inexistente dadas las competencias estatales en la materia, tiene el matiz de situar a los Estados y sus políticas sociales dentro de la estructura transnacional. Esto implica que los postulados jurídico políticos del constitucionalismo de mercado se integran dentro del sistema del constitucionalismo multinivel, abarcando tanto a los EEMM como a la UE. Cuestión distinta es cómo se articula la convivencia de la dimensión social nacional con las demandas del vínculo económico europeo en un espacio que es calificado como gobernanza multinivel. Esto significa que el Estado es todavía el actor central en la regulación de las infraestructuras públicas, de forma que la transición hacía la política social de la integración negativa resulta en una reconstrucción del Estado tradicional ${ }^{49}$.

Hasta aquí la formulación de la propuesta nos parece correcta. Los cambios producidos no son expresión de la debilidad del Estado, porque la contradicción no se establece entre la integración negativa y el Estado, sino entre ésta y una forma determinada de Estado, el Estado social. Deducir del constitucionalismo de mercado un debilitamiento de los Estados implica desconocer tanto el papel político determinante en la institucionalización del mercado, como las nuevas relaciones que se establecen entre el Estado y el mercado en el constitucionalismo de mercado europeo.

No obstante, en nuestra opinión, el error de la tesis radica en desconocer, aunque se menciona implícitamente, que la gran diferencia con la "fusión institucional" 50 entre la UE y los EEMM es que el verdadero centro definidor del modelo social y de los límites para su realización es la Unión y no las autoridades nacionales. Es cierto que a tenor de la literalidad del artículo 151 del TFUE pudiera parecer que la soberanía en política social sigue siendo estatal. Pero si se conecta las políticas sociales nacionales con la decisión que consagra el constitucionalismo de mercado, autonomía del mercado, el carácter residual de la política social a nivel estatal y europeo es manifiesto. La autonomía del mercado es el criterio material de delimitación de los espacios de realización de lo social. En el espacio transnacional europeo la debilidad de la intervención de la Unión, junto con la subordinación de los objetivos sociales al vínculo económico. En el ámbito nacional, los EEMM carecen de un margen de maniobra absoluto para definir sus políticas sociales porque no pueden comprometer el proyecto de la constitución económica europea.

${ }^{49}$ LOUIS, J-V., "A legal and institutional approach for building a monetary union", en Common Market Law Review, n. ${ }^{\circ}$ 35, 1998, p. 73.

50 ROMETSCH, D., y WESSELS, W., The EU and the Member States: towards an institutional fusion?, ed., Manchester University Press, Reino Unido. 1996. 


\subsection{La organización del modelo social supranacional desde los parámetros del gobierno europeo de la economía como única vía para superar el déficit de la integración positiva}

Para que el modelo social europeo pueda situarse en pie de igualdad con la GEE mejorada no es suficiente con un traspaso de las políticas sociales nacionales y consiguiente definición a escala europea. Tampoco con una federalización de aspectos relevantes de la política económica. La cesión de mayores cotas de soberanía que reste peso a la intergubernamentalidad decisoria. La mutualización de la deuda y el control del déficit a nivel europeo, como correlato necesario para la superación de la crisis; la apuesta por un marco financiero, presupuestario y económico integrado vía unión bancaria, fiscal y económica: el incremento de la legitimidad democrática de las instituciones europeas: y el fortalecimiento del papel de los interlocutores sociales en la participación del diseño de las medidas legislativas europeas $^{51}$. Ciertamente se trata de medidas que abordan cuestiones claves que afectarían al diseño político jurídico de la GEE, empero sin llegar a comprometerlo. Lo que demuestra la dificultad de afirmar la conexión del ámbito europeo con la integración positiva del Estado social. Sobre todo, porque el marco teórico desde el que se definen las funciones que los EEMM y las instituciones europeas deben asumir es el mismo, la GEE. Nos encontramos con argumentos que tratan de conciliar los contenidos de uno y otro modelo, como si los términos de la relación GEE/gobierno europeo pudieran conjugarse en una multiplicidad de significados llamados a complementarse entre sí. La gobernanza económica implica un cambio radical en la concepción de la política, una dinámica dirigida a la privatización de las decisiones políticas.

Por eso nuestra propuesta es distinta, porque sólo trasladando al espacio supranacional europeo el gobierno de la economía caracterizado por una primacía de la política, será factible una intervención pública en la economía que condicione el sistema. Esta constitucionalización en los Tratados de un gobierno de la economía implica, lógicamente, una ruptura de la vigente decisión jurídico-política. Propuesta que excede del grueso de reflexiones que adoptan una perspectiva de cooperación integración positiva-integración negativa sin abandonar el constitucionalismo de mercado europeo.

Como segundo paso, la adhesión de la UE a la CSE revisada. Esto es, un proceso de verdadera interacción de la CSE en la normativa social eu-

51 RUIZ-HUERTA, J., "La unión fiscal como base para refrendar la Europa social. Propuestas para una política fiscal común en la Unión Europea”, en Gaceta sindical: reflexión y debate, n. ${ }^{\circ}$ 18, 2012, pp. 191-206. HOLLAND, S., "Bonos de la Unión, eurobonos y un New Deal para Europa", en Gaceta sindical: reflexión y debate, n. ${ }^{\circ}$ 17, 2011, pp. 91-110. 
ropea. Caracterizada como principio general del Derecho de la Unión, se posibilitaría un incremento del nivel de protección de los derechos sociales contemplados por la CDFUE que se beneficiaría de las tutelas-garantías contenidas en el documento social y, especialmente, de la jurisprudencia emanada por el Comité Europeo de Derechos Sociales (CEDS). Al mismo tiempo, sería necesario considerar a la totalidad del articulado de la CSE como "núcleo duro", revisando la opción actual de normas vinculantes a la carta. Se trata de superar el estigma programático de los derechos sociales para avanzar en su consolidación como verdaderos derechos fundamentales, cruciales para la dignidad del ser humano, exigibles y accionables ante los Tribunales.

En tercer lugar, frente a la flexibilidad teórica de las normas del PEC postulada por la Comisión, cuando un Estado miembro tenga que hacer frente a desequilibrios macroeconómicos esto no ha de conllevar una criminalización del gasto público en políticas de protección social, frente a una mejora de la estrategia de acumulación del capital. La adopción de medidas de reducción del déficit público ha de tener su correlato en el análisis del impacto social de dichas medidas de tal forma que se garantice su pervivencia más allá de los límites asistenciales.

En cuarto lugar, correspondencia entre sanciones por vulnerar los vínculos presupuestarios y sanciones por vulnerar el incumplimiento del vínculo social. Resulta paradójico que se reconozca explícitamente que algunos EEMM han incumplido el objetivo de combatir la exclusión social a través de recortes drásticos en gasto público mientras crece la demanda de protección social, y que la única solución que se ofrezca sea una recriminación verbal de su responsabilidad social con la reducción de la pobreza. 